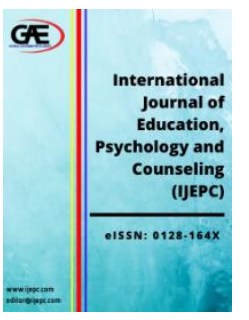

\author{
INTERNATIONAL JOURNAL OF \\ EDUCATION, PSYCHOLOGY \\ AND COUNSELLING \\ (IJEPC) \\ www.ijepc.com
}

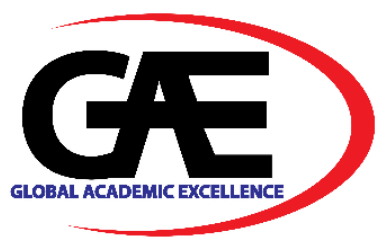

\title{
THE ROLE OF TRAIT FORGIVENESS IN MARITAL CONTENTMENT AMONG MARRIED COUPLES IN CITAM ASSEMBLIES, NAIROBI, KENYA
}

\author{
Veronica Kaari Makena $^{1 *}$, Ruth Njeri Kamunyu ${ }^{2}$ \\ 1 Department of Counseling Psychology, Pan Africa Christian University, Kenya \\ Email: veronica.makena@pacuniversity.ac.ke \\ 2 Department of Counseling Psychology, Pan Africa Christian University, Kenya \\ Email: ruthkamunyu@ pacuniversity.ac.ke \\ * Corresponding Author
}

\begin{abstract}
Article Info:
Article history:

Received date: 22.06 .2021

Revised date: 15.07 .2021

Accepted date: 05.09.2021

Published date: 09.09.2021

To cite this document:

Makena, V. K., \& Kamunyu, R. N. (2021). The Role Of Trait Forgiveness In Marital Contentment Among Married Couples In Citam Assemblies, Nairobi, Kenya. International Journal of Education, Psychology and Counselling, 6 (42), 383-398.
\end{abstract}

DOI: $10.35631 / \mathrm{IJEPC} .642030$.

This work is licensed under $\underline{\mathrm{CC} B Y} 4.0$

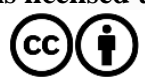

\section{Abstract:}

In most marriages, marital problems are encountered once in a while. Couples who have very happy marriages also encounter problems in their relationship with each other due to an offense committed by the spouse. For a couple to maintain a healthy marital relationship, they need to have the ability to forgive each other. Through forgiveness, married partners become more like Christ and invite the Holy Spirit to enable them to show their love for the spouse and build a safe and holy relationship that could bring contentment. The study examined the role of trait forgiveness in marital contentment among married men and women selected in two Christ Is the Answer Ministries (CITAM) assemblies in Nairobi, namely Woodley and Valley Road. The objectives of the study were to examine the role of trait forgiveness on marital contentment and to investigate how commitment, empathy, and communication affect the relationship between forgiveness and marital contentment. A mixed-methods design was used to collect data using questionnaires and a focus group discussion guide. Results showed a very strong positive correlation between trait forgiveness and marital contentment with a relatively high composite score being obtained for trait forgiveness. Results revealed themes of intimacy, patience, affirmation, self-control, reflection, and praying together on the moderating role of commitment, empathy, and communication. This calls for its magnification in both counseling practice and marriage and family therapy sessions as a sustainable antidote to marital contentment under relational stress, especially among Christian couples. Counseling practitioners should therefore emphasize the principle of forgiveness as the key to healing emotional wounds that are caused by offenses that manifest in the course of a marriage. 
Keywords:

Trait Forgiveness, Marital Contentment, Commitment, Communication, Empathy

\section{Introduction}

The capacity of a partner being able to forgive their partner has been found out to be an important factor in maintaining healthy marital relationships (Fincham 2009). Fincham suggested that forgiveness is an important part of contentment in marriages since forgiveness is seen as a chance to restart, to rebuild and to make better. Forgiveness is defined as a practice that dissolves anger feelings that are as a result of betrayal of one partner in a relationship (DiBlasio \& Benda, 2008). Forgiveness is a decision made by those who feel betrayed to lay aside their bitterness and fury towards those who offend them. Allemand, Steiner and Hill (2013) proposed that forgiveness is a choice that a person makes consciously with a lot of empathy to reconcile with those who offend them.

Through forgiveness, married partners become more like Christ and invite the Holy Spirit to enable them to show their love for the spouse and build a safe and holy relationship that could bring contentment. Married couples often times try as much as possible to be considerate of the feelings of their partner every time they are making decisions as a way of preserving the close relationship (Arya \& Kaushik, 2015). Although partners are generally loving, offences and transgressions happen in their relationship, and they end up hurting each other deeply. That is when forgiveness becomes imperative in the relationship (DiBlasio \& Benda, 2008).

The family serves as the main source of social support for many families in the world as well as in Kenya. Spouses who have marriages that are considered strong feel a sense of meaning in their lives which also acts as a protective factor against life's stress (Fincham, Beach \& Davila, 2010). A couples' deepest connection and emotional needs are satisfied by intimate relationships, but this also becomes a source of some of their most distressing hurts. When partners hurt each other, it is possible to develop feelings of anger and resentment, and this creates a conflict in the marriage and disrupts the harmony in the relationship. One way of handling this kind of a challenge would be through exercising forgiveness by both partners in the relationship (Maio, Thomas \& Fincham, 2008). Studies conducted by Bono, McCullough \& Root, (2008), advanced that many aspects that are closely related to marital satisfaction include love, understanding, commitment, communication, mutual trust, respect, support, thoughts, loyalty, intimacy and concern for each other coupled with mutual expression of feelings and experiences.

Findings from research have revealed that there are other circumstances that forecast the decision of whether or not a partner who has been wronged will easily forgive the offending partner. For instance, McCullough (2008) found that many people are willing to forgive their partners when an apology for the offence is given. Sometimes, forgiveness will occur because the person has empathy for the offender and does not dwell on the wrong or offence that was committed (Fincham \& Beach, 2007). Forgiveness can be conceptualized at different levels of specificity such as a trait, as an inclination towards a specific relationship partner and as an offense-specific response. Trait forgiveness occurs across relationships, offenses and situations. The tendency to forgive a particular relationship partner (Fincham et al., 2007) is to forgive him or her across multiple offenses. Offense-specific forgiveness is defined as a single Copyright (C) GLOBAL ACADEMIC EXCELLENCE (M) SDN BHD - All rights reserved 


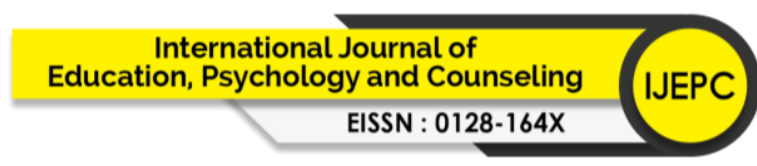

Volume 6 Issue 42 (September 2021) PP. 383-398

DOI 10.35631/IJEPC.642030

act of forgiveness for a specific offense within a particular interpersonal context (Allemand, Amberg, Fincham \& Zimprich, 2007).

Despite the findings from studies that have been conducted and showed some benefits of forgiveness and its effectiveness in marital satisfaction, few of the studies have addressed forgiveness in respect to trait forgiveness and how it affects marital contentment. Several studies that have been conducted indicated that forgiveness predicts sustained relationship contentment in the face of partner transgressions (Fincham \& Beach, 2007) but failed to explore the mechanisms of doing it and hence this study. At the same time, trait level forgiveness is studied but the studies tend to ignore the importance of relationship context for understanding forgiveness in relationship to marital contentment. This study sought to explore the relationship context of the married couples.

\section{Literature Review}

There are several points that will be discussed under literature review including forgiveness, trait forgiveness, communication and empathy.

\section{Forgiveness}

Usually in life, the people that we love most are likely to hurt us (Fincham, 2009). When relational offences happen to relationships that are very close, they have a tendency to produce tough destructive feelings and they have the possibility of disrupting and disturbing the relationship. For people to cope with that kind of relational pain and hurt, forgiveness is fundamental. When partners are in a romantic relationship, they find it easier to forgive as a way of sacrifice for the benefit of the partners and this brings greater commitment (Braithwaite, Selby \& Fincham, 2011), reductions in anger, grief, anxiety, depression and problematic conflict (Fincham, 2009). The cross-sectional and longitudinal studies of forgiveness have revealed that more satisfying relationships are promoted through forgiveness (Karremans \& Lange, 2009).

For a marriage partner to forgive another, the one forgiving needs to be conscious that they have been hurt. If there is no offence, hurt or wrongdoing, then the partner has nothing to forgive (Allemand, Job, Christen \& Keller, 2008). In analyzing forgiveness, McCullough (2008) distinguished three scenarios in which the term could be applied: as a trait of personality, as a response to a definite wrongdoing, and as a representative of communal units. In the study, the researcher considered forgiveness both a response to a particular interpersonal wrongdoing or offence and as a trait. It is likely that in trait forgiveness, an individual can possess trait forgiveness without a partner having committed any offense (McNulty, 2011). In this instance, it is necessary for studies to be conducted and examine forgiveness as a trait where partners forgive each other even when there is no particular offence that they are referring to or committed. A common element of the definition of forgiveness include a healing reaction from a negative event by both withdrawing negative sentiments and by increasing positive sentiments.

Alongside other researchers, (Zuccarini, Johnson, Dalgleish \& Makinen, 2013), Johnson (2009) viewed forgiveness as a process. In contrast to Johnson's focus on attachment, Worthington (2008) acknowledged that much of the previous research on forgiveness had been rooted in religion. In addition, Fehr, Gelfand and Nag, (2010) stated that the foundational understanding of forgiveness was that Christians should work to forgive others just as God had 


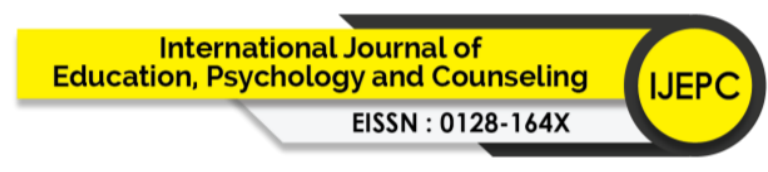

Volume 6 Issue 42 (September 2021) PP. 383-398

DOI 10.35631/IJEPC.642030

forgiven them. Fehr et al., (2010) sought to leverage the culture of forgiveness in religious communities and applied that approach to marriage and family therapy. In the model, clients were encouraged to confess their transgressions to each other. Couples would then take turns empathetically responding to the other's confession, and it was believed that this brought forgiveness.

In addition to findings of Fehr et al., (2010), other studies examined the beneficial results of forgiveness. For example, researchers found out that forgiveness plays a major role in promoting relationship restoration after a transgression (Steiner, Allemand \& McCullough, (2011), minimize the chances of that relationship ending, (Hall \& Fincham, 2008), enables strategies of resolving future conflicts (DiBlasio \& Brenda, 2008), and promote future relationship well-being (Fincham, Beach \& Davila, 2010). Forgiveness has been found to facilitate couples in more effectively addressing relationship issues instead of holding grudges or engaging in defensive reactions that impede reconciliation (Wieselquist, 2009). Some of the studies conducted focused on the benefits that accrued from the partners forgiveness due to transgressions committed. Some of the findings revealed that the benefits were physical benefits for those who forgive (Paleari, Regalia \& Fincham, 2011), and other researchers found out those who were committed to the relationship and forgave their partner enjoyed psychological benefits (Williamson \& Gonzales, 2007). Little research has been conducted on the effect of forgiveness experienced by the partner who committed the transgression.

\section{Trait Forgiveness}

According to Bell, Kamble and Fincham (2018), trait forgiveness is explained as the tendency for an individual to forgive across many situations and time. Like other traits of personality, trait forgiveness is an unchanging distinct difference (Bell et al., 2018). Individuals who have a high sense of practicing forgiveness any time they are wronged believe that there is no hurt that cannot be forgiven, unlike individuals who have no regard of forgiveness whenever it happens and tend to interpret offenses as not worthy of forgiveness. Forgiveness as a temperament can be expected to compare with forgiveness as a developmental expression of that temperament (Zuccarini et al., 2013). People who have been offended do not feel the desire or need to forgive especially where the offenses are perceived as intentional and a subject of rumination. Offenders who try and understand the perspective of the offender are willing to forgive and consider the offence as mild.

The study by Maio et al., (2008) carried out an assessment on the general tendency to forgive using hypothetical offenses and asked participants to indicate how likely they would forgive the offender. In the study, Maio et al., (2008) found that trait forgiveness slightly and prospectively predicted relationship satisfaction for husbands twelve to fourteen months after initial participation and responses. Trait forgiveness has been highlighted as a foundation for reactions of forgiveness to particular transgressions. Allemand et al., (2013) replicated prior findings (Kachadourian, Fincham \& Davila, 2009), and found a relationship between trait forgiveness and relationship contentment. They found out that a partner who was willing to continuously forgive the partner and give them a new chance to change, reform and stop the mistakes of the past would help and flourish the marital relationship and build individual and relational resources, which may have an encouraging influence on relationship satisfaction and contentment. Kachadourian et al., (2009) noted that a satisfying relationship with a good relational climate may be an important supporting resource in times of interpersonal hurts or offences and is likely to provide a context that facilitates trait forgiveness. The studies by 


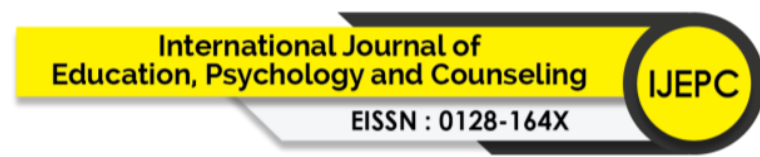

Volume 6 Issue 42 (September 2021) PP. 383-398

DOI 10.35631/IJEPC.642030

McNulty, (2008) revealed that forgiveness positively relates to communication that is constructive in close relationships. Correspondingly, Karremans and Van Lange (2009) found trait forgiveness to be predictive of pro-relationship behaviors and motivations.

\section{Commitment}

It is generally believed that both forgiveness and commitment stimulate and enhance prorelationship motives and the two constructs are therefore positively related (Gordon, Hughes, Tomcik, Dixon \& Litzinger, 2009; Hall \& Fincham, 2008; Karremans \& Van Lange, 2009). The authors suggested that commitment could lead to faster forgiveness as individuals who have a high sense of commitment may be more inspired to forgive their partner simply because they would like to maintain the current relationship. Forgiveness has to occur following a relational transgression, in order for damaged closeness and commitment to be restored since commitment facilitate forgiveness (McCullough, 2008). McCullough indicated the partner who has been wronged needed to stop harboring the wrong done so that they can be close to the partner who committed the offence. Further to this perspective, Bono, McCullough and Root, (2008) offered continuing confirmation that forgiveness stimulates an increase in commitment.

Basically, strong commitment promotes positive mental events, pro-relationship motives and forgiveness because it is a fundamental property of relationships. Allemand et al., (2008) defined commitment in terms of having intent to persist, long-term orientation and psychological attachment. The three authors suggested that commitment develops as a result of increasing satisfaction and gratifying important needs, like the needs for intimacy or security, declining alternatives where important needs could not effectively be gratified by alternative partners, friends or kin and increasing resources such as personal identity and effort (Hill, Hasty \& Moore, 2011). The act of commitment could also be understood as introspection where a person understands his or her attitudes after observing his or her own obvious behavior. People who often forgive label themselves as forgiving by putting the incident behind them once they have forgiven (Braithwaite et al., 2011). Worthington and Scherer (2010) proposed that the act of commitment brings an attitude change in a marriage.

\section{Empathy}

Studies conducted by Strayer and Eisenberg (2011) revealed that it is not easy to explain how forgiveness works to bring about change in a person's feelings, attitudes and thoughts. Worthington and Jennings (2010) suggested one model that aid in the explanation of the process of forgiveness and postulated that all forgiveness begins with a pain, hurt or wound. The hurt can be inflicted when a partner violates limitations of trust that existed whether physically or psychologically and the victim will attack or decide to withdraw from the offender as a result. Partners who respond in this manner affect the relationship in a negative sense by destroying any love that existed and unless the two people address the pain and wound, then the relationship will eventually die (Wade, Worthington \& Haake, 2009). In addition, Worthington and Jennings (2010), proposed that if there is empathy, a partner will be able to forgive and this will help to heal the wound and potentially repair the relationship. Kmiec (2009) indicated that for there to be empathy in forgiveness, the person who has been wronged needs to feel empathy for the offender and also experience a sense of humility and realize that they also have the capacity to harm others just like the offender (Sandage \& Worthington, 2010). It is therefore necessary that these conditions are met for forgiveness to happen. 


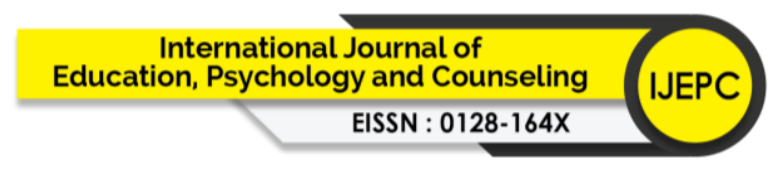

Volume 6 Issue 42 (September 2021) PP. 383-398

DOI 10.35631/IJEPC.642030

Empathy has also been suggested as a significant social and cognitive variable which plays a dynamic role in predicting and understanding behavior of human beings (Dhillon \& Jha, 2018). According to Hill, Hasty and Moore (2011), empathy lies at the heart of higher levels of differentiation and requires development of self-awareness. The more a person is aware of their personal emotions, the more skilled they are in discerning and responding to the emotions of another person (Baghel \& Pradhan, 2014). Furthermore, Waldron and Kelley (2008), postulate that empathy is a primary assisting factor leading to forgiveness, and it entails a shift in attention from one's own experience toward the experience of one's partner and an active effort to understand another person's perception of an interpersonal event as if one were that other person (Fife, Weeks \& Stellberg-Filbert, 2013). Fife et al., (2013) discussed empathy as a factor of gift to forgive and proposed a model of forgiveness process which they divided into four phases. First, after a couple has identified a problem, which is the uncovering phase, they make the decision to forgive, which is the decision phase. This is followed by the work phase which offers the best explanation of how exactly forgiveness takes place within the individual.

\section{Communication}

Studies that have been conducted by Merolla and Shuang (2011) revealed that partners communicate forgiveness in three general ways. One way is direct communication which is forgiving in an obvious way, indirect communication which is forgiving by downplaying the offense, and conditional communicating which is forgiving with stipulations. Further studies by Waldron and Kelley (2008) revealed that as transgressions grow in severity, partners are more likely to use conditional and less likely to use indirect forgiveness. Additionally, some forms of forgiveness were linked to relational outcomes. Merolla and Shuang (2011) studied romantic relationships and friendships and used quantitative and qualitative techniques to explore the use of direct, indirect and conditional forgiveness. Results showed that there were differences in forgiveness communication as a function of offense attributes (Schumann, 2012). It was noted that the offended partners were more likely to communicate forgiveness conditionally or indirectly if the severity of the transgression continued to increase and blameworthiness on offender responsibility increased. Similar to Waldron and Kelley (2008), conditional forgiveness was linked to reduced interpersonal satisfaction. Conditional forgiveness was also a factor that played a role in the amount of ongoing negativity that offended partners felt.

Moreover, communication of forgiveness for an offence that has been committed may lead to more harm when it is not communicated in a skillful way according to Wade, Worthington and Haake (2009). In their study, they found out that if forgiveness is offered in a manner that is not skillful, the offended partner may feel put down or humiliated even though the forgiveness offered is genuine. Pronouncements of forgiveness may be deliberately abused and can be used intentionally to convey scorn. Similarly, statements of forgiveness that are made verbally may not reflect true feelings as Worthington and Jennings (2010) found out and labeled those kinds of pronouncements of forgiveness without accompanying internal changes as hypocritical forgiveness (Kelley, 2006).

Additional studies undertaken on communicating forgiveness (Hargrave \& Sells, 2010) revealed that forgiveness could easily be confused with an explicit statement of forgiveness. It is therefore important to explore how forgiveness is communicated between people as they interact in their daily lives. In addition to approaches that are not direct or indirect in communicating forgiveness, Sandage and Worthington Jr. (2010) found that some people 


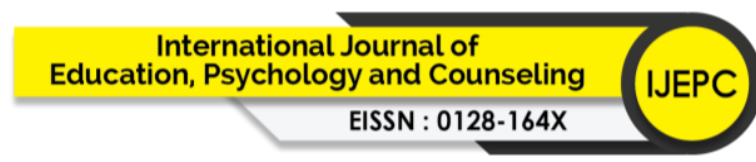

Volume 6 Issue 42 (September 2021) PP. 383-398

DOI 10.35631/IJEPC.642030

offered forgiveness by giving conditions that needed to be fulfilled first before forgiving. When a clinician is able to witness effective communication between partners that leads to marital forgiveness, it is possible to note and encourage ways that can be adapted in expressing forgiveness that leads to healthy relationships.

\section{Marital Contentment}

Research exploring marital contentment and satisfaction started with publications many years ago. In general, the results of the marital contentment literature suggest that marriages in which spouses are more satisfied are less likely to end in divorce. The research on marital satisfaction has a long history (Rezaei, 2012). The first published studies about marital contentment define marital contentment as a state in which both husband and wife feel happy and contented with being married and living with each other. Rezaei (2012) believed that marital contentment is the overlap or the alignment of the existing conditions and the expected situations. When partners in romantic relationships have resources because of the investments that they put in the relationship, they will be willing to act in a forgiving manner more easily than if they had not invested in the relationship at all. Partners who have a high quality relationship will overlook the hurt many times because they have a long-term orientation of wanting to preserve the relationship. Research carried out by Rye, Fleri, Moore, Worthington Jr and Wade, (2012) revealed that partners in high quality relationship apologise and communicate remorse more easily that partners in low-quality relationships.

\section{Role of Forgiveness in Couple Relationships}

In a study conducted on the role of forgiveness in couple relationships, (Paleari, Regalia \& Fincham, 2011), it was found out that the tendency of forgiveness in close relationships has an influence on couple's satisfaction level. The study revealed that individuals who are in a longterm marriage indicated that the willingness to forgive is an important factor that elongates and maintains marital relationships (Arya \& Kaushik, 2015). Evidence that forgiveness plays an important role in maintaining healthy romantic relationships is indeed accumulating (Bono et al., 2008), with greater commitment and willingness to sacrifice for the benefit of a romantic partner.

When forgiveness is offered, relationships are restored with new found harmony and trust (Gordon et al., 2009). It is believed where forgiveness is offered, this could improve any problems that are existing in the relationship and this prevents future problems before they begin. Forgiveness is also known to stimulate marital adjustment and may have an effect on overall relationship contentment (McCullough, 2008). Not surprisingly, Fehr et al., (2010) found that spouses believe that the willingness to forgive and be forgiven is one of the most important characteristics for marital contentment and longevity.

Forgiveness has been linked to many positive outcomes in close relationships. A number of studies have shown that forgiveness is strongly and positively related to the core relationship constructs. Several studies have indicated a positive relationship between relationship satisfaction and forgiveness (Baghel \& Pradhan, 2014; Fincham \& Beach, 2010; Tuli \& Mehrotra, 2017). It appears that the association between forgiveness and relationship quality may be bidirectional. There is emerging evidence that marital quality predicts later forgiveness as well as data that forgiveness predicts later marital satisfaction (Baghel et al., 2014). In the concluding remarks of a study conducted by Tuli and Mehrotra (2017), they established that the key element of happy and long lasting marriages is forgiveness. Forgiveness serves as a 


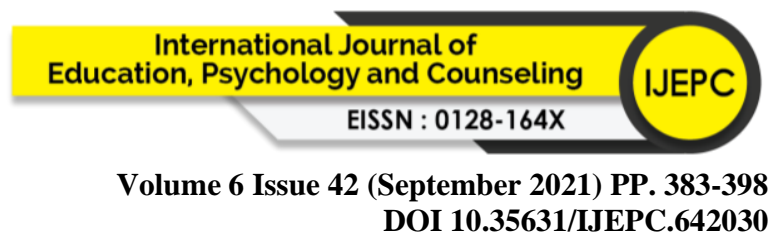

lubricant to boost the love relationship of a couple as it is an ongoing attitude of wanting the partner with his or her imperfections and irritations. Misunderstandings in marriage are inevitable and therefore, couples must learn to forgive each other.

\section{Research Methodology}

Mixed methods design was used by combining quantitative and qualitative approaches. This involved a descriptive survey which, according to Mugenda (2008), is one in which information is collected without changing the environment. It was the most suitable for this study because it was used to obtain information concerning the current status and characteristics of the population to describe what exists with respect to the variables under investigation (Hennink, Hutter \& Bailey, 2011). Descriptive study was also used because it reduced the data collected to manageable form (Smith, Devane, Begley \& Clarke, 2011). As a method of assisting the reader in understanding the data distribution, visual aids such as graphs and charts were used.

\section{Results}

\section{Descriptive Analysis of Trait Forgiveness}

Trait forgiveness was measured using 16 items that describe possible feelings, thoughts and behaviors that respondents were experiencing at the moment in response to an offence committed against them by their spouse. Table 1 presents the mean (M) and standard deviation (SD) scores of the items on a 5-point scale from 1 (strongly disagree) to 5 (strongly agree).

Table 1: Mean and Standard Deviation of Trait Forgiveness Items

\begin{tabular}{lcc}
\hline ITEM & M & SD \\
\hline $\begin{array}{l}\text { Since my spouse offended me, I have done my best to restore my } \\
\text { relationship with him/her }\end{array}$ & 4.11 & 0.97 \\
\hline $\begin{array}{l}\text { Although she/he hurt me, I definitely put what happened aside so } \\
\text { that we could resume our relationship }\end{array}$ & 3.94 & 1.09 \\
\hline I forgave my spouse completely, thoroughly & 3.77 & 1.16 \\
\hline I have always forgiven those who have hurt me & 3.64 & 1.04 \\
\hline $\begin{array}{l}\text { I try to forgive my spouse even when she/he doesn't feel guilty } \\
\text { for what they did }\end{array}$ & 3.59 & 1.97 \\
\hline \begin{tabular}{l} 
I soon forgave my spouse after he/she offended me \\
\hline I can forgive my spouse for almost anything
\end{tabular} & 3.46 & 1.04 \\
\hline I can forgive and forget an insult & 3.32 & 1.09 \\
\hline $\begin{array}{l}\text { Even after I forgive someone, things often come back to me that } \\
\text { I resent }\end{array}$ & 2.98 & 1.15 \\
\hline $\begin{array}{l}\text { Since my spouse wronged me by his behaviour, it becomes easy } \\
\text { for me to get angry with him/her }\end{array}$ & 2.59 & 1.17 \\
\hline There are some things that I could never forgive my spouse & 2.47 & 1.16 \\
\hline $\begin{array}{l}\text { Since my spouse offended me, I have been less willing to talk to } \\
\text { him/her }\end{array}$ & 2.38 & 1.23 \\
\hline \begin{tabular}{l} 
I make my spouse feel guilty for what happened \\
\hline $\begin{array}{l}\text { The event of what happened makes it hard for me to be loving } \\
\text { towards my spouse }\end{array}$
\end{tabular} & 2.29 & 1.15 \\
\hline \begin{tabular}{l} 
right $\odot$ GLOBAL ACADEMIC EXCELLENCE (M) SDN BHD - All rights reserved \\
\hline
\end{tabular} & 1.18 \\
\hline
\end{tabular}


Volume 6 Issue 42 (September 2021) PP. 383-398

DOI 10.35631/IJEPC.642030

\begin{tabular}{lcc}
\hline ITEM & M & SD \\
\hline $\begin{array}{l}\text { I would like to behave toward my spouse in the same way that } \\
\text { she/he behaved toward me. }\end{array}$ & 2.19 & 1.25 \\
\hline $\begin{array}{l}\text { I still hold some grudge against my spouse because of what } \\
\text { she/he did }\end{array}$ & 2.03 & 1.13 \\
\hline
\end{tabular}

Table 1 reveals that a high mean score was obtained on a 5-point scale regarding respondents doing their best to forgive their spouse after being offended $(\mathrm{M}=4.11, \mathrm{SD}=0.97)$. This means that most of the respondents agreed that they did their best to find contentment in the marriage. This indicates a high commitment to marriage by the respondents, suggesting that respondents high on trait forgiveness were potentially highly committed to their marital relationship. This is in line with McCullough's (2008) hypothesis that commitment could drive forgiveness as highly committed individuals may not want to jeopardise their relationship and are therefore more interested in forgiving their partner simply because they intend to remain in their current relationship.

The table also presents a high mean score regarding respondents' putting aside what happened in order to resume relationship after being hurt by the spouse $(\mathrm{M}=3.94, \mathrm{SD}=1.09)$. This indicates that most of the respondents agreed that they discounted hurtful episodes in order to restore their marital relationship. It means that the respondents had an understanding that in order for damaged closeness and commitment to be restored, forgiveness has to occur following a relational transgression, since commitment facilitate forgiveness which is also consistent with McCullough's (2008) views.

Further, a high mean score was obtained with regards to respondents forgiving their spouse thoroughly and completely $(\mathrm{M}=3.77, \mathrm{SD}=1.16)$ implying that most of the respondents agreed that they were completely forgiving. Similarly, a high mean score was realized with regards to whether respondents always forgave those who hurt them $(\mathrm{M}=3.64, \mathrm{SD}=1.04)$, as most of the respondents agreed that they were always forgiving. Concerning whether respondents tried to forgive their spouse even when she/he doesn't feel guilty for what they did, the mean score obtained was high $(\mathrm{M}=3.59, \mathrm{SD}=1.97)$, which means that most of the respondents agreed that they tried to be forgiving even when their spouse felt no remorse for their offenses. Collectively, these results imply that respondents displayed high levels of trait forgiveness, further signaling high levels of commitment to their marriages. These findings affirm the observations made by Rye et al., (2012) that suggest that couples in a marriage may be more prepared to behave in a forgiving way and partners in high-quality relationships may have a long-term inclination that might influence them to overlook hurts in order to maximize the likelihood of preserving the relationship.

Table 1 however shows that a moderate mean score was computed on a 5-point scale $(M=3.46$, $\mathrm{SD}=1.04)$ on whether respondents soon forgave their spouse after offending them. This means that respondents were non-committal regarding the practice of immediate forgiveness. The table also suggests that respondents were also non-committal with respect to whether they could actually forgive an insult as implied in the moderate mean score obtained $(\mathrm{M}=3.29$, $\mathrm{SD}=1.10$ ). Similarly, a moderate mean score was obtained on a 5-point scale regarding whether things always came back that respondent resented even after forgiving. This means that respondents were indifferent on this respect too. Concerning whether respondents got annoyed by their spouse more easily since the offense, a moderately low mean score was realized Copyright (C) GLOBAL ACADEMIC EXCELLENCE (M) SDN BHD - All rights reserved 


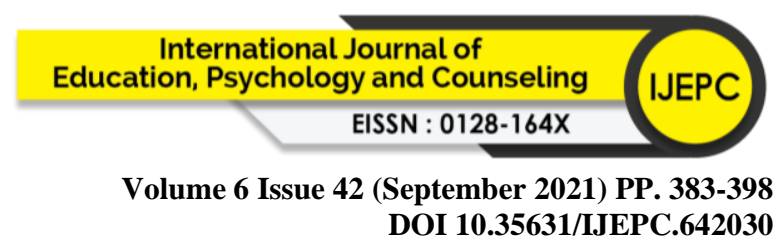

$(\mathrm{M}=2.59, \mathrm{SD}=1.17)$, implying that respondents neither agreed nor disagreed with the statement. These results suggest that respondents exhibited moderate levels of trait forgiveness when it comes to immediately forgiving a partner, forgiving insults and taking offense.

\section{Inferential Analysis of The Influence of Trait Forgiveness in Marital Contentment}

Spearman's rank correlation analysis was performed on marital contentment composite mean score and trait forgiveness composite mean score. The results are presented in Table 2 at $p<.01$. The table indicates that there was a strong positive correlation between trait forgiveness and marital contentment $(r=.515, p<.01, N=107)$. This implies that marital contentment increased with increase in trait forgiveness. The finding supports prior results of a study by both Kachadour et al., (2009) and Allemand et al., (2013) which associated trait forgiveness with relationship contentment. A conclusion can be made from the tendency observed in research findings that a continuing willingness to forgive and give a new chance to the offending spouse and to allow him or her to leave his or her mistakes in the past and make a fresh start actually fosters relationships with positive implications on relationship satisfaction and contentment.

Table 2: Correlation Between Trait Forgiveness and Marital Contentment

\begin{tabular}{|c|c|c|c|}
\hline \multicolumn{2}{|l|}{ Spearman's rho } & Marital & Trait \\
\hline \multirow{3}{*}{ Marital Contentment } & Correlation Coefficient & 1.000 & \\
\hline & Sig. (2-tailed) & & \\
\hline & $\mathrm{N}$ & 107 & \\
\hline \multirow{3}{*}{ Trait Forgiveness } & Correlation Coefficient & $.515^{* *}$ & 1.000 \\
\hline & Sig. (2-tailed) & .000 & \\
\hline & $\mathrm{N}$ & 107 & 107 \\
\hline
\end{tabular}

Table 2 reveals that the mean score in terms of whether there were some things for which respondents could never forgive their spouse was low $(\mathrm{M}=2.47, \mathrm{SD}=1.16)$. This implies that most of the respondents disagreed that there were some offenses that they could never forgive. Also, a low mean score was established concerning respondents' less willingness to talk to their spouse since being offended $(\mathrm{M}=2.38, \mathrm{SD}=1.23)$, meaning that they disagreed that they were less willing to talk to their offensive spouse. Similarly, a low mean score was obtained on a 5-point scale concerning whether respondents made their spouse feel guilty for what happened $(\mathrm{M}=2.29, \mathrm{SD}=1.15)$. This means that respondents disagreed that they made their spouse feel guilty of their offenses. A low mean score was also realized on a 5-point scale regarding whether respondents found it difficult to be loving towards their spouse $(M=2.21$, $\mathrm{SD}=1.18$ ). Asked whether they would like to behave towards their spouse in the same way that the spouse behaved towards them, the mean score obtained was low $(\mathrm{M}=2.19, \mathrm{SD}=1.25)$. This means that respondents disagreed with the statement. The table also indicates that the mean score obtained for holding of a grudge against the spouse because of what happened was low $(\mathrm{M}=2.03, \mathrm{SD}=1.13)$, implying that most of the respondents disagreed that they held some grudge against the spouse. These low mean scores suggest that respondents manifested many attributes of trait forgiveness as theorized by Bell et al., (2018). It means that the respondents espoused and adhered to the spirit of forgiveness as promoted by CITAM, which is anchored on Scripture which puts emphasis on forgiving others as God has forgiven us (CITAM Strategic Plan, 2016). 


\section{Respondents' Level of Forgiveness and Marital Contentment}

Table 3: Composite Scores for Forgiveness and Marital Contentment

\begin{tabular}{lcr}
\hline Variable & M & SD \\
\hline Marital contentment & 3.53 & 0.66 \\
Trait forgiveness & 3.52 & 0.53 \\
Episodic forgiveness & 3.18 & 0.85 \\
\hline
\end{tabular}

The results in Table 3 indicate that on a scale of 1 to 5 , the level of marital contentment of respondents was generally high $(\mathrm{M}=3.53, \mathrm{SD}=0.66)$, which depicts a certain degree of marital satisfaction among the respondents. This agrees with the definitive meaning of marital contentment, which Rezaei (2012) conceptualize as a people's perceived evaluation of the marriage and the extent to which needs and desires of both spouses are satisfied. Similarly, a relatively high composite score was obtained for trait forgiveness $(\mathrm{M}=3.52, \mathrm{SD}=0.53)$, which means that respondents were generally forgiving in their marriages. It can be inferred from this finding that the members of the MCCGs, as Christians, considered the principle of forgiveness as part of their relationship with God and their spouses in line with doctrinal teachings of the church (CITAM Strategic Plan, 2016). Comparatively, episodic forgiveness recorded a lower general score on a scale of 1 to $5(\mathrm{M}=3.18, \mathrm{SD}=0.85)$, suggesting that respondents were somewhat likely to forgive offending episodes in their marital relationships. What this finding implies is that not all hypothetical cases of offenses were easily forgivable by the respondents and some offenses must be put into context. This agrees with the viewpoint of Fincham et al., (2010) who argue that episodic forgiveness appear to be influenced by the relational context.

\section{How Commitment Moderate the Relationship Between Forgiveness and Marital Contentment}

Analysis of responses to three questions testing the construct "commitment" revealed six recurring themes across the views of focused group discussion participants on how they resolved various aspects of marital conflicts. These six themes, which demonstrated commitment of respondents to their marriage, were apology, outing, mediation, dialogue, prompt resolution of issues, and tension relief through sports and tears. The following excerpts exemplify these emerging themes:

“...he goes ahead and says 'sorry' which has really helped" (female participant 1).

"We talk it out and go out for dinner or lunch" (male participant 1 ).

"We solve it over a cup of coffee or dinner" (male participant 2).

"We resolved never to let the sun go down before resolving our matter" (female participant 2).

"We involved a third party" (female participant 3 ).

"We try to face the issue - Go out and talks about it" (female participant 4).

"I process it by crying it out and after that feels so relieved and even afterwards, I am able to smile even to him" (female participant 5).

"Physical activities, like football, to release tension. Together we can even play games at home like Tennis which my wife loves" (male participant 3 ).

"We go for a movie or walk" (male participant 4).

From the findings, it can be inferred that apology signals commitment which makes the environment conductive for forgiveness on the part of the offended spouse and this potentially 


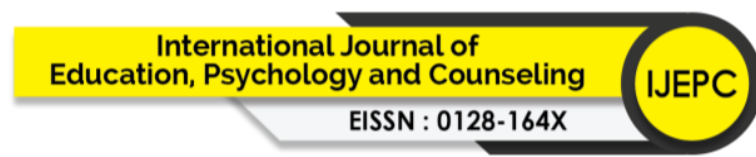

Volume 6 Issue 42 (September 2021) PP. 383-398

DOI 10.35631/IJEPC.642030

explains the high marital contentment score obtained. This agrees with the findings of McCullough (2008) which suggested that people are more likely to forgive their partners when they receive an apology from the offender. It means that an apology is among the situational factor that potentially moderate the relationship between forgiveness and marital contentment. As expressed in the verbatim comments, the word "sorry" goes a long way in restoring relationship after an offense.

As implied in the findings, the theme of "outing" stood out as a mechanism through which forgiveness is potentially catalyzed and marriage is spiced up, with positive implications on marital contentment. It appears that talking over lunch/coffee, or just going out helped couples take a break from the environment of tension. In addition, prompt resolution of issues potentially ensured that unresolved issues did not pile up and mount pressure on the couples that could make it difficult for spouses to forgive each other. This affirms the argument by Kachadourian et al., (2009) that a relationship with satisfaction with a good interpersonal environment may be an important supporting resource in times of interpersonal hurts or offences and is likely to provide a context that facilitates trait forgiveness. The responses also suggest that commitment manifested through mediation in conflict resolution. This depicts a recognition of the importance of a third party in helping couples put things into perspective and regulating the climate of discussion.

From the findings, engagement in different tension relief activities was also a means of fostering commitment and a mechanism through which a state of mind conducive for forgiveness was promoted by the respondents. Respondents derived therapeutic benefits of activities like crying (for the female gender) and sports (for the male gender) which relieved tension caused by their anger reaction to the offending spouse. This helped dissipate feelings of resentment towards the spouse and enabled them to forgive, with potentially positive implications on marital contentment.

\section{How Empathy Moderate the Relationship Between Forgiveness and Marital Contentment}

The construct "empathy" was represented by understanding, goodwill and willingness to reach out during conflict. Results revealed themes of intimacy, patience, affirmation, self-control, reflection and praying together. These themes underlay the responses of participants as reflected in the following verbatim examples:

"I hold and embrace her more. This way I ensure we stick together and somehow it will affirm to her that I care" (male participant 1).

"My spouse doesn't have mood swings at all. I thank God for that" (male participant 2).

"My spouse is composed and therefore works out about the moods until they overcome" (Female participant 3).

"I hold the hand of my spouse and stay close to her" (Male participant 5).

"I affirm care and compassion" (Male participant 6 ).

"We hug and sit together to watch a movie" (Female participant 4 ).

"We hold hands and pray for each other" (Female participant 6 ).

From the results, empathy was demonstrated in actions that symbolized a caring and loving demeanor from the spouse. Such actions like holding hands, hugging and embracing provides signals of commitment despite the offense, thereby motivating the offended spouse to 


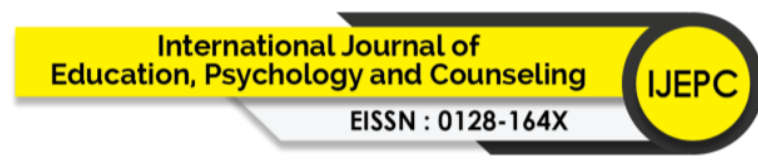

Volume 6 Issue 42 (September 2021) PP. 383-398

DOI 10.35631/IJEPC.642030

reciprocate by forgiving their partner and as a result, contentment with the marriage is enhanced. This is in line with studies conducted by Bono et al., (2008) which showed that various factors such as love, commitment, understanding, intimacy and concern for each other coupled with mutual expression of feelings, thoughts, and experiences are closely related to marital satisfaction.

\section{How Communication Moderate the Relationship Between Forgiveness and Marital Contentment}

The construct "communication" was represented by a question about how participants described their communication pattern and what evidence they got from their spouse that they were understood. Two predominant communication themes namely: direct communication and indirect communication were elicited. The themes identified were evident in the following verbatim comments:

\footnotetext{
"Body language determines I am understood" (Female participant 2).

"The spouse responds to give feedback. Explanation is given. Direct actions on what was communicated" (Female participant 3 ).

"Has to be attentive to the communication. Feedback" (Male participant 1).

"Sometimes retreats to have one-on-one communication" (Male participant 2).

"Response from the spouse, and also body language. Direct feedback you receive is a key pointer" (Female participant 5).
}

The results suggest that respondents used a combination of both direct and indirect communication to convey forgiveness and understanding which potentially contributed to marital contentment. This is in line with a study by Merolla \& Shuang (2011) which identified these two communication archetypes as forms of communicating forgiveness. The findings were that older respondents were more than the younger respondents in the MCCGs implying that the older generation were more interested in investing in their marriage. On the factor of length of marriage, the findings were that those with many years and few years of marriage attended the MCCG, implying that the respondents were committed to strengthen their marriage.

Inferential analysis revealed a strong positive correlation between trait forgiveness and marital contentment $(r=.515, p<.01, N=107)$, with a relatively high composite score being obtained for trait forgiveness on a 5-point scale $(\mathrm{M}=3.52, \mathrm{SD}=0.53)$ and a similar score being obtained for marital contentment $(\mathrm{M}=3.53, \mathrm{SD}=0.66)$. Content analysis of the construct "commitment" revealed six recurring themes across the views of FGD participants. These six themes, which demonstrated commitment of respondents to their marriage, were apology, outing, mediation, dialogue, prompt resolution of issues, and tension relief through sports and tears. The construct "empathy" was represented by understanding, goodwill and willingness to reach out during conflict. Results revealed themes of intimacy, patience, affirmation, self-control, reflection and praying together. For the construct "communication", two predominant themes namely: direct communication and indirect communication were elicited.

\section{Recommendations}

Counseling practitioners should emphasize the principle of forgiveness as the key to healing emotional wounds that are caused by offenses that manifest in the course of a marriage. Specifically for Christian couples, trait forgiveness should be promoted not only in obedience 


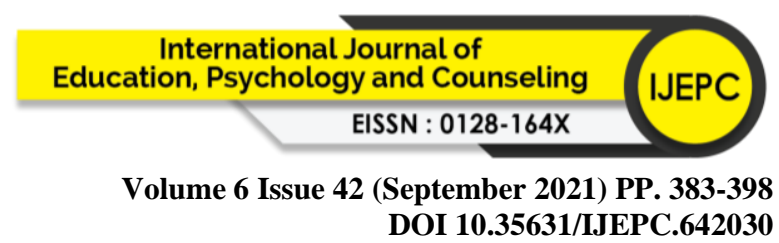

to God but as a way of enhancing marital contentment during moments of marital conflict and tensions.

The concept of trait forgiveness should be integrated in all marriage counseling programs such as pre-marital counseling trainings, marriage seminars and other marital enhancement programs as a distinct discipline. Couples should be encouraged to develop habits of praying for their spouse, letting go and letting God, and having compassion for the spouse as ways through which they can deal with offenses and stay happily married. In this respect, the researcher proposed to publish a manual that can be used during the seminars and workshops.

Married Couples Care Groups (MCCG) leadership and membership should take deliberate steps to initiate discourse on practical ways couples can make the environment conductive for forgiveness after an alleged transgression. It is in such forums where married individuals can share and compare notes on what works. In such forums, participants can learn effective ways of communication, how they can demonstrate marital commitment and empathy both as the offending and as the offended spouse.

\section{Areas for Further Research}

Since this study only focused on two CITAM churches, a CITAM-wide study could be launched to increase reliability of statistical estimates and to enhance generalizability of the study findings. A future study should control for potential effect of Christian religious beliefs by conducting a comparative study of MCCGs and married non-Christian care-groups. A similar study could be conducted among married couples in other churches to establish whether the same variables predict forgiveness among couples from different religious denominations.

\section{References}

Allemand, M., Steiner, M. \& Hill, L.P. (2013). Effects of a forgiveness intervention for older adults. Journal of Counselling Psychology, 60(2):279-286.

Allemand, M., Amberg, I., Zimprich, D., \& Fincham, F.D. (2007). The role of trait forgiveness and relationship satisfaction in episodic forgiveness. Journal of Social and Clinical Psychology, 26, 199-217.

Allemand, M., Job, V., Christen, S., \& Keller, M. (2008). Forgivingness and action orientation Personality and Individual Differences, 45(8), 762-766.

Arya, B., \& Kaushik, N. (2015). Forgiveness and relationship quality: A dyadic perspective. Indian Journal of Health and Wellbeing, 6(1), 57-61.

Baghel, S., \& Pradhan, M. (2014). Self-efficacy as a moderator between empathy and forgiveness relationship. Indian Journal of Positive Psychology, 5(4), 388-392.

Bell, C. A., Kamble, A. V., \& Fincham F. D. (2018). Forgiveness, Attributions, and Marital Quality in U.S. and Indian Marriages. Journal of Couple and Relationship Therapy 23, $1-18$.

Bono, G., McCullough, M. E., \& Root, L. M. (2008). Forgiveness, feeling connected to others, and well-being: Two longitudinal studies. Personality and Social Psychology Bulletin, $34,182-195$.

Braithwaite, S., Selby, E., \& Fincham, F. D. (2011). Forgiveness and relationship satisfaction: Mediating mechanisms. Journal of Family Psychology, 25, 551-559.

CITAM. (2016). Strategic Plan. Retrieved from http://www.citam.org

Dhillon, R., \& Jha, N. K. (2018). A study of differences in empathy and sociomoral reasoning in offenders and non-offenders. Indian Journal of Health and Wellbeing, 9(3), 380-383. 


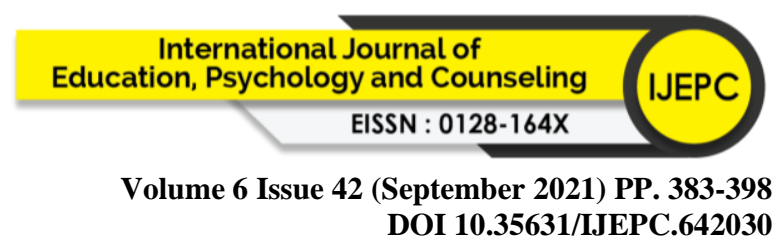

DiBlasio, F. A., \& Benda, B. B. (2008). Forgiveness intervention with married couples: Two empirical analyses. Journal of Psychology and Christianity, 27, 150-158.

Fehr, R., Gelfand, M. J., \& Nag, M. (2010). The road to forgiveness: A meta-analytic synthesis of its situational and dispositional correlates. Psychological Bulletin, 136(5), 894-914.

Fife, S. T., Weeks, G. R., \& Stellberg-Filbert, J. (2013). Facilitating forgiveness in the treatment of infidelity: an interpersonal model. Journal of Family Therapy, 35(4), 343 367

Fincham, F. D. (2009). Forgiveness: Integral to a science of close relationships? In M. Mikulincer and P. Shaver (Eds.), Prosocial motives, emotions, and behavior (pp. 347365). Washington, DC: APA Books.

Fincham, F. D., Beach, S. R. H., \& Davila, J. (2010). Longitudinal relations between forgiveness and conflict resolution in marriage. Journal of Family Psychology, 21, 542545.

Gordon, K. C., Hughes, F. M., Tomcik, N. D., Dixon, L. J., \& Litzinger, S. C. (2009). Widening spheres of impact: The role of forgiveness in marital and family functioning. Journal of Family Psychology, 23, 1-13.

Hall, J. H., \& Fincham, F. D. (2008). The temporal course of self-forgiveness. Journal of Social and Clinical Psychology, 27, 174-202.

Hargrave, T. D., \& Sells, J. N. (2010. The development of a forgiveness scale. Journal of Marital and Family Therapy, 23(1), 41-63.

Hennink, M., Hutter, I., \& Bailey, A., (2011). Qualitative research methods. New Delhi: SAGE publications Inc.

Hill, W. E., Hasty, C., \& Moore, C. J. (2011). Differentiation of Self and the Process of Forgiveness: A Clinical Perspective for Couple and Family Therapy. Australian and New Zealand Journal of Family Therapy, 32(1), 43-57

Johnson, S. M. (2009). Emotionally focused couple therapy. In A. S. Gurman (Ed.), Clinical handbook of couples therapy (4th ed.; pp. 107-137). New York, NY: Guilford Press.

Kachadourian, L. K., Fincham, F. D., \& Davila, J. (2009). The tendency to forgive in dating and married couples: The role of attachment and relationship satisfaction. Personal Relationships, 11, 373-393.

Karremans, J. C., \& Van Lange, P. A. M. (2009). Back to caring after being hurt: The role of forgiveness. European Journal of Social Psychology, 34, 207-227.

Kelley, D. L. (2006). The communication of forgiveness. Communication Studies, 49(3), 117.

Kmiec, S. M. (2009). An analysis of sex differences in empathy and forgiveness. A Thesis published by The Faculty of the Department of Psychology of East Carolina University.

Maio, G. R., Thomas, G., \& Fincham, F. D, (2008). Unraveling the role of forgiveness in family relationships. Journal of Personality and Social Psychology, 94, 307-319.

McCullough, M. E. (2008). Beyond revenge: The evolution of the forgiveness instinct. New York, NY: Jossey-Bass.

McNulty, J. K. (2011). Forgiveness increases the likelihood of subsequent partner transgressions in marriage. Journal of Family Psychology, 24, 787-790

Merolla, A. J., \& Shuang Yue, Z. (2011). In the wake of transgressions: Examining forgiveness communication in personal relationships. Personal Relationships, 18(1), 79-95.

Mugenda A. G. (2008). Social Sciences Research: Theory and Principles. ART Press. Nairobi.

Paleari, F. G., Regalia, C., \& Fincham, F. (2009). Marital quality, forgiveness, empathy, and rumination: A longitudinal analysis. Personality and Social Psychology Bulletin, 31, $368-378$. 


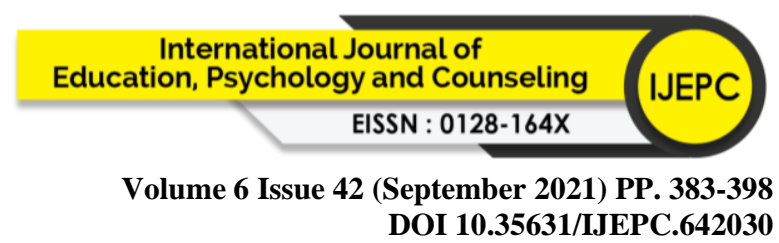

Rezaei A. (2012). A comparison of the importance of characteristics of marriage and marital satisfaction between Iranian and Norwegian couples, M.A. thesis, Islamic Azad University of Arak, Science and Research Branch

Rye, M. S., Fleri, A. M., Moore, C. D., Worthington, E. L., Jr., \& Wade, N. G. (2012). Evaluation of an intervention designed to help divorced parents forgive their ex-spouse. Journal of Divorce and Remarriage, 53, $231 \square 245$.

Sandage, S. J., \& Worthington Jr., E. L. (2010). Comparison of Two Group Interventions to Promote Forgiveness: Empathy as a Mediator of Change. Journal of Mental Health Counseling, 32(1), 35-57.

Schumann, K. (2012). Does love mean never having to say sorry? Associations between relationship satisfaction, perceived apology sincerity, and forgiveness. Journal of Social and Personal Relationships, 29, 997-1010.

Smith, V., Devane, D., Begley, C. M., \& Clarke, M. (2011). Methodology in conducting a systematic review of healthcare interventions. BMC Medical Research Methodology, 11(1), 15-20.

Steiner, N., Allemand, M., \& McCullough, M. E. (2011). Age differences in forgivingness: The role of transgression frequency and intensity. Journal of Research in Personality, 45(6), 670-678

Strayer, J, \& Eisenberg, N. (2011). Empathy and its Development. New York: Cambridge University Press; 1987. pp. 389-398

Tuli, G., \& Mehrotra, S. (2017). Forgiveness as a factor in marital quality. Indian Journal of Health and Wellbeing, 8(10), 1265-1267.

Wade, N. G., Worthington, E. L., Jr., \& Haake, S. (2009). Promoting forgiveness: Comparison of explicit forgiveness interventions with an alternative treatment. Journal of Counseling and Development, 87, 143-151

Waldron, V. R. \& Kelley, D. L. (2008) Communicating Forgiveness. Thousand Oaks, CA: Sage.

Wieselquist, J. (2009). Interpersonal forgiveness, trust, and the investment model of commitment. Journal of Social and Personal Relationships, 26, 531-548.

Williamson, I., \& Gonzales, M. H. (2007). The subjective experience of forgiveness: Positive construals of the forgiveness experience. Journal of Social and Clinical Psychology, 26(4), 407-446.

Worthington, E. L., Jr., \& Jennings, D. J. (2010). Interventions to promote forgiveness in couple and family context: Conceptualization, review, and analysis. Journal of Psychology and Theology, 38, 231-245.

Worthington, Jr E. L. \& Scherer, M. (2010): Forgiveness is an emotion focused coping strategy that can reduce health risks and promote health resilience: theory, review and hypotheses. Psychology and Health, 19:3, 385-405

Zuccarini, D., Johnson, S. M., Dalgleish, T.L., \& Makinen, J. A. (2013). Forgiveness and reconciliation in emotionally focused therapy for couples: The client change process and therapist interventions. Journal of Marital and Family Therapy, 39(2), 148-162. 